\title{
Resenha do livro A Gramática Política no Brasil: Clientelismo e Insulamento Burocrático.
}

Gisele Braga Bastos

\author{
Gisele Braga Bastos \\ Doutoranda em Sociologia Política pela Universidade Estadual do Norte \\ Fluminense, mestre em Ciências Sociais pela Universidade Federal de \\ Juiz de Fora. \\ E-mail: gibragabastos@gmail.com \\ ORCID: https://orcid.org/0000-0002-0688-3081
}

Em análise dedicada a captar como a temática do clientelismo vem sendo tratada na Ciência Política brasileira, nos últimos trinta anos, realizamos um levantamento sobre o tema do clientelismo nos seis periódicos com melhor avaliação na área da CAPES de Ciência Política e Relações Internacionais no período de 1990 a 2017, disponíveis no Scielo.

Nossas questões de partida foram: o tema do clientelismo vem recebendo a atenção dos cientistas sociais e políticos brasileiros? Em caso positivo, como o tema vem sendo abordado nas últimas três décadas? Os periódicos analisados foram: Brazilian Political Science Review (BPSR), Dados, Lua Nova, Opinião Pública (OP), Revista de Sociologia e Política (RSP) e a Revista Brasileira de Ciências Sociais (RBCS). Nosso primeiro passo foi verificar, no total dos 2627 artigos contabilizados, quantos tinham pelo menos uma menção às palavras-chave, pesquisadas em português, espanhol e inglês. Dos seis periódicos analisados, apenas a Brazilian Political Science Review publica artigos, exclusivamente, em inglês. As palavras consideradas para o filtro foram clientelismo (ou no inglês "clientelism"), clientelista (ou no inglês "clientelistic"). O período coberto foi de 1990 a 2017 (só entraram os números de 2017 que já haviam sido lançados no momento em que iniciamos a análise). Por estarmos trabalhando com um grande volume de dados, optamos por utilizar um software de análise de dados qualitativosi. Encontramos 364 artigos que faziam, pelo menos, uma menção a uma destas palavras, o que nos dá uma média de 60,7 artigos por periódico. Nosso universo de análise foi composto, portanto, por estes 364 artigos.

O campeão de citações nos estudos dedicados à temática do clientelismo político é o livro de Edson Nunes "A gramática política do Brasil: clientelismo, corporativismo e insulamento burocrático" recentemente reeditado e objeto da presente resenha. Seguido do clássico artigo de José Murilo de Carvalho "Mandonismo, coronelismo, clientelismo: uma discussão conceitual". Em seguida, aparece o livro de Eli Diniz "Voto e máquina política: patronagem e clientelismo no Rio de Janeiro". Neste livro, Diniz analisa a formação do MDB no Rio de Janeiro, a trajetória de suas principais correntes e do líder Chagas Freitas em torno do qual se originou o chaguismo. Em quarto lugar em número de citações está o livro de Richard Graham "Patronage and Politics in Nineteenth-Century Brazil". O quinto em número de citações é "Microfundamentos do Clientelismo Político no Brasil: 1959-1963" de autoria de Fabiano Guilherme dos Santos, aparece também sua tese de doutorado intitulada "Teoria de decisões legislativas: microfundamentos do clientelismo político no Brasil", defendida no antigo Instituto de Pesquisa Universitário do Rio de Janeiro (IUPERJ) e "Clientelismo como escolha racional" publicado no livro Pluralismo, Espaço Social e Pesquisa, em 1995. Por último, em sexto lugar entre os mais citados, registramos quatro trabalhos de Carl Landé que se voltam para uma discussão teórico-conceitual do clientelismo e suas 
Gisele Braga Bastos

relações diádicas e em rede, sendo um deles sobre redes e grupos no Sudeste asiático. Landé, de fato, é uma referência internacional importante nos estudos sobre o tema do clientelismo e um dos autores que mais contribuíram para a discussão conceitual; surpreende que tenha sido citado somente oito vezes nas referências bibliográficas dos 364 artigos analisados.

O livro "A Gramática Política do Brasil. Clientelismo e Insulamento Burocrático" de Edson de Oliveira Nunes, resultado de seu doutoramento na Universidade de Berkeley na Califórnia, tem sido revisitado desde sua primeira edição em 1996, sendo recorrentemente mobilizado e o principal referencial teórico de muitos estudos que abordam o clientelismo no Brasil, seja direta ou indiretamente. No estudo teórico, apresentado em seu doutoramento, agora na quinta edição pela editora Garamond Universitária, Nunes (2017) define, pautado em uma análise histórica dos governos desde os anos 1930, a coexistência de quatro padrões de relação ou "gramáticas" entre Estado e sociedade: clientelismo, corporativismo, insulamento burocrático e universalismo de procedimentos. $\mathrm{O}$ autor busca demonstrar a adaptabilidade do clientelismo frente à nova realidade democrática e ao processo de industrialização e liberalização do mercado.

O foco de Nunes (2017) recai sobre o processo de construção institucional resultante da adoção do capitalismo moderno que, em tese, traria a marca da impessoalidade às instituições políticas. $\mathrm{O}$ argumento é o de que, contrariando os postulados de Weber e Polanyi, nem todas as novas instituições brasileiras foram compostas pela lógica impessoal das modernas relações de mercado, em grande parte em função do curto espaço de tempo em que foram criadas e em decorrência da forte influência e modus operandi clientelista das oligarquias do país. Nessa direção, o autor busca demonstrar os fatores históricos pungentes para a formação da gramática política do Brasil, destacando como o corporativismo, o insulamento burocrático e o universalismo de procedimentos não substituem, e sim, incorporam-se ao clientelismo pré-existente (NUNES, 2017 :31).

Nunes (2017) inova ao empreender o enfrentamento da lógica explicativa dicotômica - centro versus periferia, atrasado versus moderno - para apresentar a discussão entre os modos de produção capitalista e as gramáticas políticas por ele tipificadas. Em sua análise coloca o clientelismo como oposto ao universalismo de procedimentos e como mecanismo de operação política persistente na formação do Estado Moderno presente na lógica partidária e política (em seu estudo analisa a partir da década de 1930) destacando Juscelino Kubitschek e Getúlio Vargas como exímios operadores do clientelismo associado ao corporativismo na década de 1950.

O trabalho é inovador por fazer frente à lógica explicativa fundada na ideia de dois Brasis. Para o autor há a necessidade de compreender as interações existentes entre estruturas políticas e transformação econômica, e não reduzir a análise à lógica economicista. Dessa forma destaca a necessidade de compreensão dos elementos de forma multidimensional com o objetivo de superar as observações gerais, na direção de análises sistemáticas que permitam erigir um arcabouço analítico que dê conta de captar as diversas dimensões das interações Estado versus sociedade.

Nunes (2017) destaca em sua análise a força do familismo e das lealdades hereditárias nas instituições políticas brasileiras e a diferença entre a noção norte-americana de família nucleada em pai, mãe e filhos e a noção de família associada à parentela presente na organização social brasileira. Além disso, destaca a presença institucionalizada do personalismo e do jeitinho ilustrando a análise com a clássica definição do "sabe com quem está falando" de Roberto Da Matta (1979). Assim, conclui que "O clientelismo se manteve forte no decorrer de períodos democráticos, não definhou durante o período do autoritarismo, não foi extinto pela industrialização e não mostrou sinais de fraqueza no decorrer da abertura política" (ibidem, p.54). 0 autor destaca ainda que nas sociedades 
Gisele Braga Bastos

capitalistas modernas o clientelismo tende a operar em redes extensivas, e que "Em sociedades sincréticas como a brasileira ou a italiana, a lógica da troca generalizada é transferida para associações, instituições políticas, agências públicas, partidos políticos, cliques, facções" (ibidem, p.49).

Caberia entrar no debate contemporâneo da ascensão de milícias nas esferas de poder nos governos locais, estaduais e federal, nos poderes legislativo, executivo e judiciário, nas distribuições de cargos distanciadas do universalismo de procedimentos, no nepotismo cruzado, nos desvios do erário que corroem os valores democráticos e ameaçam a segurança jurídica. Não é à toa que o livro chega à sua quinta edição, o texto segue atual e o debate necessário, tanto pela presença de cliques, facções, milícias, quanto pelo argumento da adaptabilidade do fenômeno do clientelismo às demais gramáticas, e também pela anunciação de que em sociedades capitalistas modernas relações diádicas entre patróncliente seriam substituídas por redes complexas. "Estas redes envolvem uma pirâmide de relações que atravessam a sociedade de alto a baixo" (ibidem, p.53).

Atual e necessário "A gramática política do Brasil. Clientelismo, corporativismo e insulamento burocrático" em sua quinta edição é um livro fundamental que apresenta as gramáticas que perpassam os movimentos históricos de construção do Brasil desde a Primeira República, passando pelo período militar e chegando até a década de 1980. Mas não é só isso, o livro nos leva ao exercício de problematizar sobre atualidade das relações entre as quatro gramáticas e sobre a adaptabilidade do fenômeno do clientelismo.

Além de ser um excelente manual de como realizar um estudo teórico o livro tem um forte traço de estudo histórico apresentado no correr da obra e coroado nas páginas finais, onde o autor apresenta um ANEXO contendo um apanhado histórico que pretende dar conta de forma sistematizada (ano a ano) das agências, institutos, comissões e leis criadas no período de 1930 a 1945.

O livro está organizado em cinco capítulos: 1- Instituições, Política e Economia; 2Tipos de capitalismo, instituições e ação social; 3- A construção do insulamento burocrático e do corporativismo e a nacionalização do clientelismo; 4- Capitalismo, partidos políticos e insulamento burocrático no regime pós-45; 5- Mudança dentro da continuidade: velhas e novas arenas políticas no período pós-guerra. $E$, apresenta a conclusão intitulada: $O$ sistema em questão: continuidade, mudanças e perspectivas.

Como já mencionado, o livro está em sua quinta edição. Não apresenta novidades em relação às edições anteriores realizadas respectivamente em 1997, 1999, 2003 e 2010. Ainda que não haja um prefácio, nem nota do autor à quinta edição o livro apresenta os prefácios da quarta, terceira e primeira edição e replica a nota do autor escrita em 1997. É importante destacar o prefácio à primeira edição, escrito em Maio de 1996, de autoria de Luiz Carlos Bresser Pereira que destaca a validade da obra e virtuose do autor, reforçando que a maioria das teses de doutorado apresentadas no exterior morre nas bibliotecas. Se este era um elogio à época, certamente se mantêm, tanto pela importância que a tese defendida em 1984 adquiriu, quanto pelo triste cenário de manutenção das teses nas prateleiras das bibliotecas. Ainda que hoje tenhamos bancos virtuais de dissertações e teses, o que facilita o acesso, mas não resolve o problema.

A editora responsável pela publicação da quinta edição é a editora Garamond Universitária, localizada no Rio de Janeiro. Com o slogan "Bons livros, grandes autores", a editora possuí um catálogo dedicado aos temas atuais com destaque para os debates sobre meio ambiente e direitos humanos, no catálogo trazem obras com foco no comportamento e cultura contemporâneos, literatura, meio ambiente, sexualidade, política, ciências humanas, ciências sociais, filosofia, psicanálise e arte. Entre as obras com destaque em seu catálogo encontramos a edição, publicada em 2019, comemorativa de 40 anos do livro "A Aventura Sociológica: Objetividade, paixão, improviso e método na pesquisa social" organizado pelo 
Gisele Braga Bastos

mesmo autor da obra aqui resenhada. Além deste, a editora tem em seu catálogo, de autoria de Nunes: "Futuros Possíveis e Passados Indesejáveis. Selo da OAB, Provão e Avaliação do Ensino Superior" (2000), "Agências reguladoras e reforma do estado no Brasil ", "Educação Superior No Brasil" (2012), e "A Revolta das Barcas: Populismo, Violência e Conflito Político", publicado em 2006.

Voltando ao objeto da resenha, ao todo são 196 páginas, incluindo anexo e bibliografia que por si só valem uma leitura detida.

O livro é instigante e uma leitura indispensável para estudantes de história, sociologia, ciência política, economia, administração pública, políticos, administradores públicos ou curiosos interessados em compreender as relações de troca de favores por voto/apoio político, os processos de burocratização, universalismo de procedimentos e o corporativismo no Brasil.

(Recebido para publicação em julho de 2020)

(Reapresentado em setembro de 2020)

(Aprovado para publicação em dezembro de 2020)

\section{Cite esta resenha}

BASTOS, Gisele, 2020. Resenha do livro A Gramática Política no Brasil: Clientelismo e Insulamento Burocrático. Revista Estudos Políticos: a publicação semestral do Laboratório de Estudos Hum(e)anos (UFF). Rio de Janeiro, Vol.11 |N.22, pp.248 - 252, dezembro de 2020.

\section{Notas}

1. Atlas $\mathrm{Ti}$ Qualitative Data Analysis. Número da certificação: 8C5A5-F9268-1B58I-BH1N1-00A28.

\section{Bibliografia}

CARVALHO, J. (1997). Mandonismo, Coronelismo, Clientelismo: Uma Discussão Conceitual Vol. 40 ( 2 ), s.p.. Rio de Janeiro, RJ: DADOS - Revista de Ciências Sociais.

DA MATTA, R. (1990). Você sabe com quem está falando? Um ensaio sobre a distinção entre indivíduo e pessoa no Brasil, In Carnavais, malandros e heróis, pp. 146-204. Rio de Janeiro, Guanabara.

DINIZ, Eli. (1982). Voto e máquina política: patronagem e clientelismo no Rio de Janeiro. Rio de Janeiro, RJ: Paz e Terra.

GRAHAM, R. (1990). Patronage and politics in nineteenthcentury Brazil. Stanford: Stanford U.P. [Edição brasileira: Clientelismo e política no Brasil do século XIX. Rio de Janeiro, RJ: Ed. UFRJ, 1997.] 
Gisele Braga Bastos

LANDÉ, C. H. (1983). Political Clientelism in Political Studies. Retrospect and Prospects. International Political Science Review, vol. 4, no 4, pp. 435-454.

(1977). Groups politics and dyadic politics: notes for a theory. In: SCHMIDT, S.W. et al (Eds.). Friends, Followers and Factions. A Reader in political clientelism. Berkeley: University of California Press.

(1977a). Introduction : The Dyadic Basis of Clientelism. In : SCHMIDT, S. W. (ed.). Friends, Followers and Factions : A Reader in Political Clientelism. Berkeley: University of California.

(1977b). Networks and Groups in Southeast Asia : Some Observations on the Group Theory of Politics. In : SCHMIDT, S. W. (ed.). Friends, Followers and Factions : A Reader in Political Clientelism. Berkeley : University of California.

SANTOS, F. (1994), Teoria de Decisões Legislativas: Microfundamentos do Clientelismo Político no Brasil. Tese de Doutorado. IUPERJ. Rio de Janeiro.

(1995a), Microfundamentos do Clientelismo Político no Brasil: 1959-1963. 38 (3), pp. 459-496. :Dados Revista de Ciências Sociais.

(1995b), Clientelismo como Escolha Racional, in E. Reis,M. H. Tavares de Almeida e P. Fry(orgs.), Pluralismo, Espaço Social e Pesquisa. SãoPaulo, SP: Hucitec.

NUNES, E. (2017). A gramática política no Brasil: Clientelismo e insulamento burocrático. $5^{a}$ ed. Rio de Janeiro, RJ: Garamond Universitária. 